\title{
Nontypeable Haemophilus influenzae biofilms: role in chronic airway infections
}

\author{
W. Edward Swords* \\ Department of Microbiology and Immunology, Wake Forest School of Medicine, Winston-Salem, NC, USA
}

Edited by:

Michael J. Schurr, University of

Colorado, USA

Reviewed by:

Jose A. Bengoechea, Fundacion

Caubet-CIMERA Illes Balears, Spain

Michael L. Vasil, University of

Colorado Medical School, USA

\section{*Correspondence:}

W. Edward Swords, Department of

Microbiology and Immunology,

Wake Forest School of Medicine,

575 N. Patterson Avenue, 2E-034

Wake Forest Biotech Place,

Winston-Salem, North Carolina

27101, USA.

e-mail:wswords@wakehealth.edu
Like many pathogens inhabiting mucosal surfaces, nontypeable Haemophilus influenzae (NTHi) forms multicellular biofilm communities both in vitro and in various infection models. In the past 15 years much has been learned about determinants of biofilm formation by this organism and potential roles in bacterial virulence, especially in the context of chronic and recurrent infections. However, this concept has not been without some degree of controversy, and in the past some have expressed doubts about the relevance of NTHi biofilms to disease. In this review, I will summarize the present information on the composition and potential role(s) of NTHi biofilms in different clinical contexts, as well as highlight potential areas for future work.

Keywords: biofilms, chronic obstructive pulmonary disease, Haemophilus influenzae, otitis media, rhinosinusitis

\section{INTRODUCTION}

Biofilms are generically defined as multicellular microbial communities, often encased within a matrix material, which promote persistence within an environment (Costerton et al., 1995, 1987). It is now recognized that many different microbes exist in biofilms, and that the majority of persistent infections involve biofilms (Donlan, 2001, 2002; Bakaletz, 2007; Hall-Stoodley and Stoodley, 2009). Notably, biofilm communities are inherently resistant to antimicrobials and immune effectors due to multiple factors that can include lack of penetration of the biofilm matrix as well as reduced or halted metabolism of the bacteria residing within a biofilm (Fux et al., 2005; Hall-Stoodley and Stoodley, 2009).

Haemophilus influenzae is a commensal and opportunistic pathogen that is highly adapted to the human airway that is its primary environment (Erwin and Smith, 2007). The majority of $H$. influenzae strains in carriage and localized disease are the nontypeable $H$. influenzae (NTHi) strains that lack polysaccharide capsules, and are thus completely unaffected by the protective immune response generated by the Hib conjugate vaccine (Murphy and Apicella, 1987; Agrawal and Murphy, 2011). NTHi strains can persist within the airways for long periods of time during which carriage is mostly asymptomatic in healthy people (Mukundan et al., 2007). However, in circumstances where host mucosal clearance mechanisms are compromised or impaired, NTHi can cause an array of opportunistic infections that include rhinosinusitis, bronchitis, pharyngitis, and Otitis Media (OM) (Erwin and Smith, 2007).

Biofilm formation by NTHi has been the subject of a considerable amount of work and at least some degree of controversy. While there has been considerable progress on defining determinants of biofilm formation in vitro and, to some degree, the consequences of biofilms for persistence and pathogenicity in vivo, some have also expressed skepticism about whether NTHi biofilms have significance to disease (Dohar, 2007; Moxon et al., 2008). In this review I will highlight the current state of knowledge regarding determinants of biofilm formation by NTHi, as well as evidence regarding the relevance of biofilms to persistence of this organism in vivo.

\section{CLINICAL EVIDENCE}

Over the past 15 years, there have been a large number of studies that implicate biofilms in persistent infections caused by $H$. influenzae (Table $\mathbf{1}$ ). OM is an extremely common pediatric ailment that occurs in large part due to dysfunction of the Eustachian tube, resulting in impaired mucosal drainage of the middle-ear chamber and resulting infection with bacterial opportunists, including $\mathrm{NTHi}$, that normally reside in the nasopharynx. While NTHi and other bacteria may be frequently isolated from patients with $\mathrm{OM}$, middle-ear effusions from a large proportion of these patients do not yield culturable bacteria. However, in a series of important early studies, Post and colleagues showed that NTHi and other bacteria could be detected in these samples by PCR-based methods (Post et al., 1995, 1996a,b; Aul et al., 1998; Bakaletz et al., 1998; Liederman et al., 1998). Similarly, middle-ear effusion samples were shown to contain bacterial components (Dingman et al., 1998) and transcripts, indicating bacterial metabolic activity (Rayner et al., 1998). Subsequent analysis of tympanostomy tubes and tissues from patients with chronic/recurrent $\mathrm{OM}$ and tissues from experimentally infected chinchillas clearly demonstrated surface-attached bacterial biofilm communities of NTHi and other OM-related opportunists (Post, 2001; Hall-Stoodley et al., 2006; Hoa et al., 2009, 2010). Similar results have been obtained from examination of adenoids from children with chronic or recurrent OM (Hoa et al., 2009; Nistico et al., 2011), as well as in nasal tissues from 
Table 1 | Clinical presentations of Haemophilus influenzae with a biofilm component.

\begin{tabular}{|c|c|c|}
\hline Presentation & Finding & Reference \\
\hline \multirow[t]{4}{*}{ Otitis media } & Bacteria and bacterial components present in culture-negative effusion fluids & $\begin{array}{l}\text { Post et al., 1995, 1996a,b; Dingman et al., } \\
1998\end{array}$ \\
\hline & Bacterial RNA found in culture-negative effusion fluids & Rayner et al., 1998 \\
\hline & H. influenzae biofilms in middle-ear chamber of experimentally infected chinchillas & Post, 2001 \\
\hline & H. influenzae surface-attached communities in patient tissues & $\begin{array}{l}\text { Hall-Stoodley et al., 2006; Hoa et al., 2009, } \\
2010\end{array}$ \\
\hline \multirow[t]{2}{*}{ Chronic bronchitis } & Long-term persistence as evidenced by recurrent sputum cultures & Sethi et al., 2002; Murphy et al., 2004 \\
\hline & Expression of peroxiredoxin levels similar to those observed in biofilm & Murphy et al., 2005 \\
\hline Rhinosinusitis & H. influenzae surface-attached communities in patient tissues & $\begin{array}{l}\text { Foreman et al., 2009, 2011; Oncel et al., } \\
2010\end{array}$ \\
\hline
\end{tabular}

patients with rhinosinusitis (Foreman et al., 2009, 2011; Oncel et al., 2010). In the context of airway infections associated with chronic obstructive pulmonary disease (COPD), Murphy and Kirkham showed that NTHi peroxiredoxin-glutaredoxin $(p g d X)$ was expressed in vivo as evidenced by presence of antibody in patient sera (Murphy et al., 2005). Notably, levels of $\operatorname{PgdX}$ were shown to be increased in NTHi biofilms as compared to planktonic cultures, and mutants defective in $p g d X$ in four different NTHi strain backgrounds were shown to have significant impairment in biofilm formation using a static assay (Murphy et al., 2005). While much work remains to be done on this subject, it is clear that the available evidence strongly suggests the presence of biofilms within the lungs of patients with COPD. Moreover, the increase in glutaredoxin/peroxiredoxin levels may indicate that NTHi bacteria within biofilm are under oxidative stress, which is consistent with recent findings from our laboratory related to the stress-response factor Dps (Pang et al., 2012).

\section{NETs AND NTHi BIOFILMS}

One of the criticisms that has been raised regarding NTHi biofilms is the potential for killing by neutrophil extracellular traps (NETs) (Moxon et al., 2008). We thus performed experiments to address the potential role of NETs in biofilm formed during experimental OM infections (Hong et al., 2009). Using immunofluorescent staining and confocal laser scanning microscopy, we showed that NTHi bacteria are found within multicellular biofilm clusters within NET structures. Importantly, these NET/exudate masses were not correlated with clearance of $\mathrm{NTHi}$, as bacterial counts within chinchilla middle-ear cavities exhibiting macroscopically visible biofilms were significantly higher than those found within ears with no visible biofilm (Hong et al., 2009). NTHi bacteria and bacterial components were shown to initiate NET formation, and the bacteria were shown to be highly resistant to killing by NET and additional incoming neutrophils (Juneau et al., 2011). Thus, the observation of surface-attached NTHi bacteria in vivo is not likely to represent bacteria that are in the process of being cleared within a NET structure.

\section{ANTIBIOTICS AND $\boldsymbol{H}$. influenzae BIOFILMS}

As has been observed for many bacterial species, $H$. influenzae bacteria within a biofilm are inherently resistant to antibiotics. For example, Slinger and colleagues demonstrated that
$H$. influenzae biofilms are resistant/tolerant to a wide variety of clinically relevant antibiotics (Slinger et al., 2006). Starner and colleagues showed that NTHi isolates from patients with cystic fibrosis formed biofilm communities on immortalized Calu-3 cells, which were highly resistant to treatment with gentamicin (Starner et al., 2006). Notably, this group later demonstrated that lower concentrations of a variety of antibiotics significantly stimulated biofilm formation by NTHi (Starner et al., 2008). Thus, antibiotics may impact both NTHi biofilm formation and resistance of bacteria to biofilms.

\section{NTHi SURFACE COMPONENTS AND BIOFILM}

Murphy and colleagues examined biofilm formation by a number of NTHi isolates from patients with (COPD) using a static assay. Of note, the strain set examined by this group was one for which extensive data concerning persistence of individual strains within the patient airway, as well as clinical manifestations of disease, were available. While many strains in the set formed significant biofilm, there was no discernable correlation between length of persistence or severity of disease observed (Murphy and Kirkham, 2002). Later work from two different groups showed that sialylation of the bacterial surface promoted biofilm formation by NTHi in vitro in static as well as continuous-flow biofilm systems (Greiner et al., 2004; Swords et al., 2004) and persistence in animal models of OM (Swords et al., 2004; Jurcisek et al., 2005). Sialylation in biofilm was shown to involve a specific subset of sialyltransferases (Jurcisek et al., 2005) and inactivation of a TRAP-family sialic acid transporter was shown to ablate sialylation and NTHi survival within biofilms in vitro (Allen et al., 2005). Addition of phosphorylcholine to the bacterial surface was also shown to be increased in biofilm (West-Barnette et al., 2006), and to promote biofilm formation in continuous-flow systems (Hong et al., 2007b) as well as persistence in vivo (Hong et al., 2007a). This modification was also shown to significantly modulate host inflammatory responses in both in vitro cell culture systems (West-Barnette et al., 2006) and in the chinchilla OM infection model (Hong et al., 2007a).

NTHi also express type IV pili on their surfaces that mediate twitching motility and transformation-related uptake of DNA (Bakaletz et al., 2005). As in other species, the pilus was shown to be essential for biofilm formation by NTHi (Jurcisek and Bakaletz, 2007; Carruthers et al., 2012), and antibodies directed against pili are protective even against established NTHi biofilms 
(Novotny et al., 2009). Like many bacteria, NTHi bacteria also produce extracellular DNA that is important to biofilm formation (Jurcisek and Bakaletz, 2007; Izano et al., 2009). The nuclear DNA-associated protein DNABIII has an important structural role in stabilizing the extracellular DNA in the NTHi biofilm matrix, and recent work demonstrates that antibody against this factor can not only collapse biofilm structure but also mediate protection and clearance of established NTHi biofilms (Goodman et al., 2011). This work offers a particularly novel target for vaccination against biofilms formed by NTHi and, possibly, other mucosal pathogens. A summary of surface modifications/components associated with NTHi biofilms is provided in Table 2.

\section{QUORUM SIGNALING IN NONTYPEABLE $\boldsymbol{H}$. influenzae BIOFILMS}

Like many other pathogens, $H$. influenzae genomic sequences contain a homolog of the $l u x S$ genetic determinant of production of the so-called interspecies autoinducer-2 quorum signal (Harrison et al., 2005). Autoinducer-2 is a generic term for a family of derivatives of dihydroxypentanedione (DPD), which is produced by many species as a byproduct of homocysteine metabolism. For many species, the AI-2 signal can mediate density-dependent quorum signal events that coordinate communal responses in bacterial populations (Schauder et al., 2001;
Waters and Bassler, 2005). The first studies on quorum signaling by $H$. influenzae were performed by Daines and colleagues, who showed that mutation of luxS impacted the severity of OM disease but did not abolish the formation of biofilms (Daines et al., 2005). Later, our group expanded on this work to show that while luxS mutants did form biofilms, there were significant decreases in surface phosphorylcholine levels, and related decreases in biofilm thickness and density, and persistence in the chinchilla OM infection model (Armbruster et al., 2009). In this work, both genetic and physiologic complementation were shown to restore biofilm formation by luxS mutants (Armbruster et al., 2009); this was an extremely important control experiment, as these mutations can have metabolic implications (Vendeville et al., 2005; Rickard et al., 2006). Recently, our group has also demonstrated that, as in other species, RbsB can mediate uptake of DPD for NTHi strain 86-028NP (Armbruster et al., 2011); mutants lacking $r b s B$ were also shown to have biofilm defects and decreased persistence in vivo comparable to luxS mutants (Armbruster et al., 2011).

Our recent work also shows that the AI-2 quorum signals from NTHi promote biofilm formation and persistence of Moraxella catarrhalis, an opportunistic pathogen that inhabits the same mucosal environment within the airways (Armbruster et al., 2010). NTHi and M. catarrhalis formed polymicrobial biofilms that significantly enhanced antibiotic

Table 2 | Summary of current knowledge about determinants of $\boldsymbol{H}$. influenzae biofilm formation.

\begin{tabular}{|c|c|c|}
\hline Topic & Current knowledge & Reference(s) \\
\hline \multirow[t]{4}{*}{ Surface components } & Subset of LOS glycoforms & Swords et al., 2004; Greiner et al., 2004; Hong et al., 2007a,b \\
\hline & Sialylated non-LOS carbohydrate & Jurcisek et al., 2005 \\
\hline & Extracellular DNA & Jurcisek and Bakaletz, 2007; Izano et al., 2009 \\
\hline & Pili & Jurcisek and Bakaletz, 2007; Jurcisek et al., 2007 \\
\hline \multirow[t]{3}{*}{ Quorum signaling } & Promotes biofilm formation and persistence in vivo & Armbruster et al., 2009 \\
\hline & Interspecies quorum signaling & Armbruster et al., 2010; Armbruster and Swords, 2010 \\
\hline & Uptake determinant defined & Armbruster et al., 2011 \\
\hline
\end{tabular}

Current questions/topics for future study.

- How are H. influenzae quorum signals detected and what is the mechanism for enhanced biofilm?

- Are subsets of $\boldsymbol{H}$. influenzae populations undergoing regulated death/lysis to release extracellular DNA found in the biofilm matrix?

- How does biofilm impact emergence and dissemination of genetic determinants of virulence and/or antibiotic resistance?

- How do biofilms resist immune effectors in vivo?

- How do multiple $H$. influenzae strains interact within biofilm? 
resistance and bacterial persistence within the chinchilla infection model (Armbruster et al., 2010). Taken together, these data suggest that effective inhibition of quorum signaling could be a potential means to treat OM (Armbruster and Swords, 2010). A summary of current knowledge regarding NTHi quorum signaling and its role in biofilm maturation is provided in Table 2.

\section{SUMMARY AND REMAINING OUESTIONS}

Clearly, we have learned much in the past 15 years about the determinants of biofilm formation by $H$. influenzae as well as the role(s) of these biofilms during airway infections. A listing of major remaining questions is provided in Figure $\mathbf{1}$.

\section{REFERENCES}

Agrawal, A., and Murphy, T. F. (2011). Haemophilus influenzae infections in the $H$. influenzae type $\mathrm{b}$ conjugate vaccine era. J. Clin. Microbiol. 49, 3728-3732.

Allen, S., Zaleski, A., Johnston, J. W., Gibson, B. W., and Apicella, M. A. (2005). Novel sialic acid transporter of Haemophilus influenzae. Infect. Immun. 73, 5291-5300.

Armbruster, C., Byrd, M., Love, C., Juneau, R., Kock, N. D., and Swords, W. E. (2009). LuxS promotes biofilm maturation and persistence of nontypeable Haemophilus influenzae in experimental otitis media by modulation of lipooligosaccharide composition. Infect. Immun. 77, 4081-4091.

Armbruster, C. E., Hong, W., Pang, B., Weimer, K. E., Juneau, R. A., Turner, J., and Swords, W. E. (2010). Indirect pathogenicity of Haemophilus influenzae and Moraxella catarrhalis in polymicrobial otitis media occurs via interspecies quorum signaling. MBio 1, 102-110.

Armbruster, C. E., Pang, B., Murrah, K., Juneau, R. A., Perez, A. C., Weimer, K. E., and Swords, W. E. (2011). RbsB (NTHI_0632) mediates quorum signal uptake in nontypeable Haemophilus influenzae strain 86-028NP. Mol. Microbiol. 82, 836-850.

Armbruster, C. E., and Swords, W. E. (2010). Interspecies bacterial communication as a target for therapy in otitis media. Expert Rev. Anti. Infect. Ther. 8, 1067-1070.

Aul, J. J., Anderson, K. W., Wadowsky, R. M., Doyle, W. J., Kingsley, L. A., Post, J. C., and Ehrlich, G. D. (1998). Comparative evaluation of culture and PCR for the detection and determination of persistence of bacterial strains and DNAs in the Chinchilla laniger model of otitis media. Ann. Otol. Rhinol. Laryngol. 107, 508-513. biofilms in otitis media: evidence and relevance. Pediatr. Infect. Dis. J. 26, S17-S19.

Bakaletz, L. O., Baker, B. D., Jurcisek, J. A., Harrison, A., Novotny, L. A., Bookwalter, J. E., Mungur, R., and Munson, R. S. Jr. (2005). Demonstration of Type IV pilus expression and a twitching phenotype by Haemophilus influenzae. Infect. Immun. 73, 1635-1643.

Bakaletz, L. O., White, G. J., Post, J. C., and Ehrlich, G. D. (1998). Blinded multiplex PCR analyses of middle ear and nasopharyngeal fluids from chinchilla models of singleand mixed-pathogen-induced otitis media. Clin. Diagn. Lab. Immunol. 5, 219-224.

Carruthers, M. D., Tracy, E. N., Dickson, A. C., Ganser, K. B., Munson, R. S. Jr., and Bakaletz, L. O. (2012). Nontypeable Haemophilus influenzae type IV pili: biological roles of the products encoded by the 194, 1927-1933.

Costerton, J. W., Cheng, K. J., Geesey, G. G., Ladd, T. I., Nickel, J. C., Dasgupta, M., and Marrie, T. J. (1987). Bacterial biofilms in nature and disease. Annu. Rev. Microbiol. $41,435-464$.

Costerton, J. W., Lewandowski, Z., Caldwell, D. E., Korber, D. R., and Lappin-Scott, H. M. (1995). Microbial biofilms. Annu. Rev. Microbiol. 49, 711-745.

Daines, D. A., Bothwell, M., Furrer, J., Unrath, W., Nelson, K., Jarisch, J., Melrose, N., Greiner, L., Apicella, M., and Smith, A. L. (2005). Haemophilus influenzae luxS mutants form a biofilm and have increased virulence. Microb. Pathog. 39, 87-96.

Dingman, J. R., Rayner, M. G., Mishra, S., Zhang, Y., Ehrlich, M. D., Post, J. C., and Ehrlich, G. D. (1998). Correlation between presence of viable bacteria and presence of
Bakaletz, L. O. (2007). Bacterial pil and com operons. J. Bacteriol.

Certainly, there remains a significant amount to be learned about the process of biofilm formation by $H$. influenzae, and persistence of $H$. influenzae bacteria therein. However, a deeper understanding of this mode of bacterial growth seems likely to offer opportunities for new treatment modalities aimed at chronic and recurrent infections.

\section{ACKNOWLEDGMENTS}

I thank the many colleagues who have been involved in this work. Work in our laboratory is supported by grants from the NIH (DC007444, DC10051, and DC12205) and by a study contract from AstraZeneca.

endotoxin in middle-ear effusions. J. Clin. Microbiol. 36, 3417-3419.

Dohar, J. E. (2007). Evidence that otitis media is not a biofilm disease. Ear Nose Throat J. 86, 8-12.

Donlan, R. M. (2001). Biofilm formation: a clinically relevant microbiological process. Clin. Infect. Dis. 33, 1387-1392.

Donlan, R. M. (2002). Biofilms: microbial life on surfaces. Emerg. Infect. Dis. 8, 881-890.

Erwin, A. L., and Smith, A. L. (2007) Nontypeable Haemophilus influen$z a e$ : understanding virulence and commensal behavior. Trends Microbiol. 15, 355-362.

Foreman, A., Jervis-Bardy, J., and Wormald, P. J. (2011). Do biofilms contribute to the initiation and recalcitrance of chronic rhinosinusitis? Laryngoscope 121, 1085-1091.

Foreman, A., Psaltis, A. J., Tan, L. W., and Wormald, P. J. (2009). Characterization of bacterial and fungal biofilms in chronic rhinosinusitis. Am. J. Rhinol. Allergy 23 556-561.

Fux, C. A., Costerton, J. W., Stewart, P. S., and Stoodley, P. (2005). Survival strategies of infectious biofilms. Trends Microbiol. 13, 34-40.

Goodman, S. D., Obergfell, K. P., Jurcisek, J. A., Novotny, L. A. Downey, J. S., Ayala, E. A., Tjokro, N., Li, B., Justice, S. S., and Bakaletz, L. O. (2011). Biofilms can be dispersed by focusing the immune system on a common family of bacterial nucleoid-associated proteins. Mucosal Immunol. 4, 625-637.

Greiner, L., Watanabe, H., Phillips, N. J., Shao, J., Morgan, A., Zaleski, A., Gibson, B. W., and Apicella, M. A. (2004). Nontypeable Haemophilus influenzae strain 2019 produces a biofilm containing $\mathrm{N}$-acetylneuraminic acid that may mimic sialylated O-linked glycans. Infect. Immun. 72, 4249-4260.
Hall-Stoodley, L., Hu, F. Z., Gieseke, A., Nistico, L., Nguyen, D., Hayes, J. D., Forbes, M., Greenberg, D. P., Dice, B., Burrows, A., Wackym, P., Stoodley, P., Post, J. C., Ehrlich, G. D., and Kerschner, J. E. (2006) Direct detection of bacterial biofilms on the middle ear mucosa of children with chronic otitis media. JAMA 296, 202-211.

Hall-Stoodley, L., and Stoodley, P. (2009). Evolving concepts in biofilm infections. Cell Microbiol. 11, 1034-1043.

Harrison, A., Dyer, D. W., Gillaspy, A., Ray, W. C., Mungur, R., Carson, M. B., Zhong, H., Gipson, J., Gipson, M., Johnson, L. S., Lewis, L., Bakaletz, L. O., and Munson, R. S. Jr. (2005). Genomic sequence of an otitis media isolate of nontypeable Haemophilus influenzae: comparative study with $H$. influenzae serotyped, strain KW20. J. Bacteriol. 187, 4627-4636.

Hoa, M., Syamal, M., Sachdeva, L., Berk, R., and Coticchia, J. (2009). Demonstration of nasopharyngeal and middle ear mucosal biofilms in an animal model of acute otitis media. Ann. Otol. Rhinol. Laryngol. 118, 292-298.

Hoa, M., Syamal, M., Schaeffer, M. A., Sachdeva, L., Berk, R., and Coticchia, J. (2010). Biofilms and chronic otitis media: an initial exploration into the role of biofilms in the pathogenesis of chronic otitis media. Am. J. Otolaryngol. 31, 241-245.

Hoa, M., Tomovic, S., Nistico, L., HallStoodley, L., Stoodley, P., Sachdeva, L., Berk, R., and Coticchia, J. M. (2009). Identification of adenoid biofilms with middle ear pathogens in otitis-prone children utilizing SEM and FISH. Int. J. Pediatr. Otorhinolaryngol. 73 , 1242-1248.

Hong, W., Juneau, R., Pang, B., and Swords, W. E. (2009). Survival of bacterial biofilms within neutrophil 
extracellular traps promotes nontypeable Haemophilus influenzae persistence in the chinchilla model for otitis media. J. Innate Immun. 1, 215-224.

Hong, W., Mason, K., Jurcisek, J. A., Novotny, L. A., Bakaletz, L. O., and Swords, W. E. (2007a). Phosphorylcholine decreases early inflammation and promotes the establishment of stable biofilm communities of nontypeable Haemophilus influenzae strain 86-028NP in a chinchilla model of otitis media. Infect. Immun. 75, 958-965.

Hong, W., Pang, B., West-Barnette, S., and Swords, W. E. (2007b). Phosphorylcholine expression by nontypeable Haemophilus influenzae correlates with maturation of biofilm communities in vitro and in vivo. J. Bacteriol. 189, 8300-8307.

Izano, E. A., Shah, S. M., and Kaplan, J. B. (2009). Intercellular adhesion and biocide resistance in nontypeable Haemophilus influenzae biofilms. Microb. Pathog. 46, 207-213.

Juneau, R. A., Pang, B., Weimer, K. E., Armbruster, C. E., and Swords, W. E. (2011). Nontypeable Haemophilus influenzae initiates formation of neutrophil extracellular traps. Infect. Immun. 79, 431-438.

Jurcisek, J. A., and Bakaletz, L. O. (2007). Biofilms formed by nontypeable Haemophilus influenzae in vivo contain both double-stranded DNA and type IV pilin protein. J. Bacteriol. 189, 3868-3875.

Jurcisek, J. A., Bookwalter, J. E., Baker, B. D., Fernandez, S., Novotny, L. A., Munson, R. S. Jr., and Bakaletz, L. O. (2007). The PilA protein of non-typeable Haemophilus influenzae plays a role in biofilm formation, adherence to epithelial cells and colonization of the mammalian upper respiratory tract. Mol. Microbiol. 65, 1288-1299.

Jurcisek, J. A., Greiner, L., Watanabe, H., Zaleski, A., Apicella, M. A., and Bakaletz, L. O. (2005). Role of sialic acid and complex carbohydrate biosynthesis in biofilm formation by nontypeable Haemophilus influenzae in the chinchilla middle ear. Infect. Immun. 73, 3210-3218.

Liederman, E. M., Post, J. C., Aul, J. J., Sirko, D. A., White, G. J., Buchman, C. A., and Ehrlich, G. D. (1998). Analysis of adult otitis media: polymerase chain reaction versus culture for bacteria and viruses. Ann. Otol. Rhinol. Laryngol. 107, 10-16.
Moxon, E. R., Sweetman, W. A., Deadman, M. E., Ferguson, D. J., and Hood, D. W. (2008). Haemophilus influenzae biofilms: hypothesis or fact? Trends Microbiol. 16, 95-100.

Mukundan, D., Ecevit, Z., Patel, M. Marrs, C. F., and Gilsdorf, J. R. (2007). Pharyngeal colonization dynamics of Haemophilus influenzae and Haemophilus haemolyticus in healthy adult carriers. J. Clin. Microbiol. 45, 3207-3217.

Murphy, T. F., and Apicella, M. A. (1987). Nontypable Haemophilus influenzae: a review of clinical aspects, surface antigens and the human response to infection. Rev. Infect. Dis. 9, 1-15.

Murphy, T. F., Brauer, A. L., Schiffmacher, A. T., and Sethi, S. (2004). Persistent colonization by Haemophilus influenzae in chronic obstructive pulmonary disease. Am. J. Respir. Crit. Care Med. 170, 266-272.

Murphy, T. F., and Kirkham, C. (2002). Biofilm formation by nontypeable Haemophilus influenzae: strain variability, outer membrane antigen expression and role of pili. BMC Microbiol. 2, 7.

Murphy, T. F., Kirkham, C., Sethi, S., and Lesse, A. (2005). Expression of a peroxiredoxin-glutaredoxin by Haemophilus influenzae in biofilms and during human respiratory tract infection. FEMS Immunol. Med. Microbiol. 44, 81-89.

Nistico, L., Kreft, R., Gieseke, A., Coticchia, J. M., Burrows, A. Khampang, P., Liu, Y., Kerschner, J. E., Post, J. C., Lonergan, S., Sampath, R., Hu, F. Z., Ehrlich, G. D., Stoodley, P., and Hall-Stoodley, L. (2011). Adenoid reservoir for pathogenic biofilm bacteria. J. Clin. Microbiol. 49, 1411-1420.

Novotny, L. A., Adams, L. D., Kang, D. R., Wiet, G. J., Cai, X., Sethi, S., Murphy, T. F., and Bakaletz, L. O. (2009). Epitope mapping immunodominant regions of the PilA protein of nontypeable Haemophilus influenzae (NTHi) to facilitate the design of two novel chimeric vaccine candidates. Vaccine 28, 279-289.

Oncel, S., Pinar, E., Sener, G., Calli, C., and Karagoz, U. (2010). Evaluation of bacterial biofilms in chronic rhinosinusitis. J. Otolaryngol. Head Neck Surg. 39, 52-55.

Pang, B., Hong, W., Kock, N., and Swords, W. E. (2012). Dps promotes survival of nontypeable Haemophilus influenzae in biofilm communities in vitro and resistance to clearance in vivo. Front. Cell. Infect. Microbiol. (in press).

Post, J. C. (2001). Direct evidence of bacterial biofilms in otitis media. Laryngoscope 111, 2083-2094.

Post, J. C., Aul, J. J., White, G. J., Wadowsky, R. M., Zavoral, T., Tabari, R., Kerber, B., Doyle, W. J., and Ehrlich, G. D. (1996a). PCR-based detection of bacterial DNA after antimicrobial treatment is indicative of persistent, viable bacteria in the chinchilla model of otitis media. Am. J. Otolaryngol. 17, 106-111.

Post, J. C., White, G. J., Aul, J. J., Zavoral, T., Wadowsky, R. M., Zhang, Y., Preston, R. A., and Ehrlich, G. D. (1996b). Development and validation of a multiplex PCR-based assay for the upper respiratory tract bacterial pathogens Haemophilus influenzae, Streptococcus pneumoniae, and Moraxella catarrhalis. Mol. Diagn. 1, 29-39.

Post, J. C., Preston, R. A., Aul, J. J., Larkins-Pettigrew, M., RydquistWhite, J., Anderson, K. W. Wadowsky, R. M., Reagan, D. R., Walker, E. S., Kingsley, L. A., Magit, A. E., and Ehrlich, G. D. (1995). Molecular analysis of bacterial pathogens in otitis media with effusion. JAMA 273, 1598-1604.

Rayner, M. G., Zhang, Y., Gorry, M. C., Chen, Y., Post, J. C., and Ehrlich, G. D. (1998). Evidence of bacterial metabolic activity in culturenegative otitis media with effusion. JAMA 279, 296-299.

Rickard, A. H., Palmer, R. J. Jr. Blehert, D. S., Campagna, S. R., Semmelhack, M. F., Egland, P. G., Bassler, B. L., and Kolenbrander, P. E. (2006). Autoinducer 2, a concentration-dependent signal for mutualistic bacterial biofilm growth. Mol. Microbiol. 60, 1446-1456.

Schauder, S., Shokat, K., Surette, M. G., and Bassler, B. L. (2001). The LuxS family of bacterial autoinducers: biosynthesis of a novel quorum-sensing signal molecule. Mol. Microbiol. 41, 463-476.

Sethi, S., Evans, N., Grant, B. J., and Murphy, T. F. (2002). New strains of bacteria and exacerbations of chronic obstructive pulmonary disease. N. Engl. J. Med. 347, 465-471.

Slinger, R., Chan, F., Ferris, W., Yeung, S. W., St Denis, M., Gaboury, I., and Aaron, S. D. (2006). Multiple combination antibiotic susceptibility testing of nontypeable
Haemophilus influenzae biofilms. Diagn. Microbiol. Infect. Dis. 56, 247-253.

Starner, T. D., Shrout, J. D., Parsek, M. R., Appelbaum, P. C., and Kim, G. (2008). Subinhibitory concentrations of azithromycin decrease nontypeable Haemophilus influenzae biofilm formation and diminish established biofilms. Antimicrob. Agents Chemother. 52, 137-145.

Starner, T. D., Zhang, N., Kim, G., Apicella, M. A., and McCray, P. B., Jr. (2006). Haemophilus influenzae forms biofilms on airway epithelia: implications in cystic fibrosis. Am. J. Respir. Crit. Care Med. 174, 213-220.

Swords, W. E., Moore, M. L., Godzicki, L., Bukofzer, G., Mitten, M. J., and VonCannon, J. (2004). Sialylation of lipooligosaccharides promotes biofilm formation by nontypeable Haemophilus influenzae. Infect. Immun. 72, 106-113.

Vendeville, A., Winzer, K., Heurlier, K., Tang, C. M., and Hardie, K. R. (2005). Making 'sense' of metabolism: autoinducer-2, LuxS and pathogenic bacteria. Nat. Rev. Microbiol. 3, 383-396.

Waters, C. M., and Bassler, B. L. (2005). Quorum sensing: cell-to-cell communication in bacteria. Annu. Rev. Cell Dev. Biol. 21, 319-346.

West-Barnette, S., Rockel, A., and Swords, W. E. (2006). Biofilm growth increases phosphorylcholine content and decreases potency of nontypeable Haemophilus influenzae endotoxins. Infect. Immun. 74, 1828-1836.

Conflict of Interest Statement: The author declares that the research was conducted in the absence of any commercial or financial relationships that could be construed as a potential conflict of interest.

Received: 07 April 2012; accepted: 26 June 2012; published online: 25 July 2012.

Citation: Swords WE (2012) Nontypeable Haemophilus influenzae biofilms: role in chronic airway infections. Front. Cell. Inf. Microbio. 2:97. doi: 10.3389/ fcimb.2012.00097

Copyright (C) 2012 Swords. This is an open-access article distributed under the terms of the Creative Commons Attribution License, which permits use, distribution and reproduction in other forums, provided the original authors and source are credited and subject to any copyright notices concerning any thirdparty graphics etc. 